\title{
Correlation of maternal and early neonatal outcome with strength of lower segment caesarean section scar on abdominal ultrasonography
}

\author{
Bhakti Kalyankar, Vijay Kalyankar, Shrinivas Gadappa, Kokila Ashok Gaikwad
}

\begin{abstract}
Corresponding author: Dr. Kokila Ashok Gaikwad, Resident, Department of Obstetrics \& Gynaecology, Government Medical College \& Hospital, Aurangabad, Maharashtra, India; Email : drkokilagaikwad@gmail.com
\end{abstract}

Distributed under Attribution-Non Commercial - Share Alike 4.0 International (CC BY-NC-SA 4.0)

\begin{abstract}
Objectives: To assess the strength of lower uterine segment caesarean section scar after 36 completed weeks up to 40 weeks with the help of transabdominal ultrasonography (USG) and correlating with maternal and early neonatal outcome in patients with previous one LSCS. Methods: This prospective study was carried out in the Department of OBGY, GMCH, Aurangabad from 1st October 2017 to 1st October 2019. All these cases underwent transabdominal USG between 36 completed weeks to 40 weeks and scar finding noted. Based on scar thickness, cases were assigned into two groups of $\leq 3 \mathrm{~mm}$ and $>3 \mathrm{~mm}$. TOLAC (Trial of labor after caesarean) was given to cases having scar thickness $>3 \mathrm{~mm}$ and elective LSCS was done in scar thickness $\leq 3 \mathrm{~mm}$. Correlation of maternal and fetal outcome with caesarean section scar strength parameters were done. Results: Total 211 cases were included in present study. 83 cases had scar thickness $\leq 3 \mathrm{~mm}(39.3 \%)$ and 128 cases had scar thickness $>3 \mathrm{~mm}(63.6 \%)$. Strong association was seen between scar thickness and scar shape, border, continuity and echogenicity.105(49.76\%) cases were given TOLAC with successful VBAC (Vaginal birth after caesarean), in 83(39.33\%) cases had repeat elective LSCS, and $23(10.90 \%)$ cases had failed TOLAC with repeat emergency LSCS. 20 neonates needed NICU (Neonatal intensive care unit) care but causes of it were not related to scar complications. No case of obstetric hysterectomy, maternal mortality or still birth in our study. Conclusion: Successful VBAC may be advocated considering clinical factors, counseling and vigilant intrapartum management along with scar thickness of $>3 \mathrm{~mm}$, in tertiary care centres.
\end{abstract}

Keywords: TOLAC, VBAC, LSCS, scar thickness.

Caesarean section is the most common and important surgical intervention performed in modern obstetrics ${ }^{1}$. There is a significant rise in caesarean section rate in past few years ${ }^{2}$. A trial of vaginal delivery after caesarean section can save these women from the risk of repeat caesarean sections ${ }^{2}$. The frequency of uterine rupture during labour has been estimated at between $0.3 \%$ and $3.8 \%$ and that of uterine dehiscence at between $0.6 \%$ and $4 \%$ by different studies ${ }^{3}$.
Trial of labour after caesarean section remains an attractive option for many patients and leads to a successful outcome in a high proportion of cases ${ }^{4}$. Sonographic examination of the lower uterine segment (LUS) and previous lower uterine segment caesarean section scar has been used to diagnose a degree of lower uterine segment thinning, scar healing, scar dehiscence and uterine defect in uterine scar rupture cases $^{1,4,5}$. Previous studies have

Received: $13^{\text {th }}$ May 2020, Peer review completed: $17^{\text {th }}$ July 2020, Accepted: $19^{\text {th }}$ July 2020.

Kalyankar B, Kalyankar V, Gadappa S, Gaikwad KA. Correlation of maternal and early neonatal outcome with strength of lower segment caesarean section scar on abdominal ultrasonography. The New Indian Journal of OBGYN. 2021; 7(2): 142-47. 
The New Indian Journal of OBGYN. 2021 (January-June);7(2)

demonstrated that a normal lower uterine segment thickness and healthy scar predicts a safe trial of vaginal birth after caesarean section $(\mathrm{VBAC})^{6}$. There are different methods for scar evaluation like local clinical examination and transabdominal and transvaginal ultrasonography, hysteroscopy and hysterography are other method for evaluation of scar strength ${ }^{7}$ Transabdominal ultrasonography provides a reasonable accuracy with high sensitivity for scar dehiscence and rupture in $3^{\text {rd }}$ trimester of pregnancy $^{8}$.

The overall rate of caesarean section in our institute is $27 \%$ with $55 \%$ rate of repeat LSCS in cases of previous LSCS in labour. We practice trial of labour in previous caesarean deliveries in our institute. The number of cases being very high, to reduce the cases of repeat LSCS, this study becomes the need of hour has been chosen in interest of patient, society and obstetrician.

Aims and objective: To assess the strength of lower uterine segment caesarean section scar after 36 completed weeks up to 40 weeks with the help of transabdominal ultrasonography and correlating with maternal and early neonatal outcome in patients with previous one lower uterine segment caesarean section in order to decide the mode of delivery

\section{Materials and methods}

This prospective study was carried out after the institutional ethical committee approval, in the Department of Obstetrics and Gynaecology of a tertiary care centre from $1^{\text {st }}$ October 2017 to $1^{\text {st }}$ October 2019.

Inclusion criteria:

1. Pregnant women with 36 completed weeks to 40 weeks of gestational age with live singleton cephalic presentation with history of only one previous LSCS (not upper segment) and clinically estimated fetal weight $<3.5 \mathrm{~kg}$ and signed the written consent to participate in the study.

2. Previous caesarean section for non-recurrent indication.

Exclusion criteria:

1. Inter delivery interval $<18$ months and patients presenting in labour.

2. Pregnant women with history of preterm LSCS, vaginal delivery, hysterotomy, myomectomy for other reasons or a scar of unknown etiology \& uterine anomaly.
3. Pregnant women with abortion (MTP, missed, incomplete, complete abortions, vesicular mole) before and after previous scar.

After taking consent for TOLAC patient got enrolled in a study and clinical examination, transabdominal ultrasound evaluation of scar strength was done on Alokaprosoundalphax or Philips HD11 X EUSG machines in patients with full bladder. The following findings were noted in table 1.

Table 1: Sonographic parameters of scar

\begin{tabular}{ll}
\hline Ultrasound parameters & Details \\
\hline \multirow{2}{*}{ 1. Scar shape } & $\begin{array}{l}\text { 1. Triangular } \\
\text { 2. Ballooning }\end{array}$ \\
\hline \multirow{2}{*}{ 2. Scar thickness } & $<3 \mathrm{~mm}$ \\
& $>3 \mathrm{~mm}$ \\
\hline \multirow{2}{*}{ 3. Continuity } & $\begin{array}{l}1 . \text { Continue } \\
\text { 2. Discontinue }\end{array}$ \\
\hline \multirow{2}{*}{ 4. Outer scar order } & 1. Smooth \\
\hline 5. Residual myometrial thickness at & 2. Irregular \\
the level of scar in mm & $\begin{array}{l}\text { RMT measured at thinnest part of } \\
\text { scar in mm. }\end{array}$ \\
\hline 6. Scar width in mm & Maximum scar width in mm \\
7. Scar echogenicity & 1. Hypoechoic \\
& 2. Isoechoic \\
& 3. Hyperechoic \\
\hline
\end{tabular}

1. Scar shape: - The healthy scar has triangular shape and the patients with weak scar or scar dehiscence has ballooning shape.

2. Scar thickness and Residual myometrial thickness at the level of scar: It is measures in lower uterine segment with the help of curvilinear probe with frequency of 1-5 MHz. The full bladder is preferred and scar thickness is measured against full bladder and foetal head. It is measures at 3 places and thinnest measurement is noted. The thickness is measured between outer and inner border. The healthy normal scar has slightly less or about same thickness of adjacent normal lower uterine segment. The dehiscent weak scar has less scar thickness to that of adjacent normal lower uterine segment. Three layers of LUS can be identified on ultrasound: the chorioamniotic membrane with decidualized endometrium, the middle muscular layer, and the uterovesical peritoneal reflection juxtaposed with muscularis and mucosa of the bladder.

3. Scar continuity: Discontinuous scar is a feature of impeding scar rupture. The discontinuity in scar has the highest possibility of impeding scar rupture in dehiscent scar. If there is a linear anechoic area connecting outer and inner scar border along medial and lateral aspect then the scar is discontinue. The normal healthy scar has maintained continuity with adjacent normal lower uterine segment. 
The New Indian Journal of OBGYN. 2021 (January-June);7(2)

4. Outer scar border: Irregular scar border suggest poor healing of previous caesarean section scar and probability of scar dehiscence and rupture.

5. Scar width: As there is stretching in lower uterine segment as pregnancy advances, scar width usually increases. The weak scar stretches more and hence has more width than healthy scar. The ballooned scar width is more than triangular healthy scar.

6. Scar echogenicity: It is compared with adjacent normal lower uterine segment. If the scar echogenicity is same that of adjacent normal lower uterine segment then the scar is isoechoic and scar is healthy. If the echogenicity is less than that of adjacent normal lower uterine segment, it means scar is hypoechoic and the scar has poor healing and more prone to ballooning and impeding rupture. If the echogenicity is more than that of adjacent normal lower uterine segment, it means scar is hyperechoic and has more fibrous tissue and most likely a sign of healthy scar. The most important characteristic of scar is scar thickness. When scar thickness is more than $3 \mathrm{~mm}$ decision of trial of labour was taken with the consent of patient and if scar thickness was less than 3 $\mathrm{mm}$ then decision of elective repeat LSCS were taken. During labour whenever patient denied for TOLAC emergency LSCS was done. While undergoing TOLAC if emergency maternal or fetal indication for caesarean section arises then immediately patient was taken for LSCS.

Lower uterine segment was assessed intraoperatively during the caesarean delivery and graded according to the system developed by B Qureshi ${ }^{9}$ et al.

Grade 1- Normal well developed lower uterine segment.

Grade 2- Thin lower segment, content not visible.

Grade 3- Translucent lower segment, content visible

Grade 4- Well circumscribed defect or rupture of scar. study population. The mean age was 25.60 years with \pm 3.67 years of standard deviation.

Table 2: Distribution according to sociodemographic details

\begin{tabular}{|c|c|c|}
\hline Age group & No. of cases & Percentage \\
\hline$\leq 20$ year & 06 & 2.8 \\
\hline $21-25$ & 116 & 54.9 \\
\hline $26-30$ & 65 & 30.8 \\
\hline$>30$ & 24 & 11.3 \\
\hline \multicolumn{3}{|l|}{ Residence area } \\
\hline Rural & 109 & 51.6 \\
\hline Urban & 102 & 48.4 \\
\hline \multicolumn{3}{|c|}{ Socioeconomic status } \\
\hline Lower Class & 41 & 19.4 \\
\hline Upper lower class & 53 & 25.1 \\
\hline Lower middle class & 71 & 33.6 \\
\hline Upper middle class & 39 & 18.5 \\
\hline Upper class & 07 & 03.3 \\
\hline \multicolumn{3}{|l|}{ Education } \\
\hline Illiterate & 4 & 1.8 \\
\hline Primary & 57 & 27.0 \\
\hline Secondary & 65 & 30.8 \\
\hline Higher secondary & 64 & 30.3 \\
\hline Graduate \& above & 21 & 9.9 \\
\hline \multicolumn{3}{|l|}{ Gestational age } \\
\hline 37-37.6 week & 45 & 21.3 \\
\hline 38-38.6 week & 81 & 38.4 \\
\hline 39-39.6 week & 80 & 37.9 \\
\hline 40 week & 05 & 2.4 \\
\hline Total & 211 & $100.0 \%$ \\
\hline
\end{tabular}

Out of 211 study cases $83(9.33 \%)$ cases with scar thickness $<3 \mathrm{~mm}$ were selected for elective repeat caesarean section. 128 cases having scar thickness $>3 \mathrm{~mm}$ were kept for TOLAC and the number of these cases were 128 (60.67\%). Out of these 128 cases 105 (49.76\%) had successful TOLAC with VBAC. The 23 cases have failed TOLAC with repeat emergency caesarean section due to maternal or foetal indication (table 3).

Out of 83 cases which were kept for elective repeat

Uterine rupture is defined as full thickness separation of the uterine wall along with serosa. Scar dehiscence means when uterine muscle is separated but the visceral peritoneum is intact. The statistical Table 3: Distribution according to mode of delivery and scar thickness

\begin{tabular}{llll}
\hline Mode of delivery & \multicolumn{2}{c}{ Scar thickness } & \\
\cline { 2 - 3 } & $\mathbf{3} \mathbf{m m}$ & $\mathbf{3 m m}$ & Grand total \\
\hline TOLAC successful VBAC & 0 & 105 & 105 \\
Elective repeat LSCS & 83 & 0 & 83 \\
Failed TOLAC - repeat emergency LSCS & 0 & 23 & 23 \\
Grand total & 83 & 128 & 211 \\
\hline
\end{tabular}

TOLAC - Trial of labor after caesarean, VBAC - Vaginal birth after caesarean, LSCS - Lower segment tool used in our study is chi-square caesarean section.

test for independent variables and the statistical software SPSS version 23.0 was used for the analysis of data and microsoft word and excel were used to generate graphs tables etc.

\section{Results}

The total numbers of cases included in our study were 211. Table 1 shows the sociodemographic profile of the

caesarean section 39 (48.98\%) cases had thinning of lower uterine segment. 23 cases $(27.71 \%)$ had scar dehiscence. 1 case $(1.2 \%)$ had scar rupture. $20(24.09 \%)$ cases had normal well developed lower uterine segment with no significant difference between scar site and adjacent lower segment. Out of 23 cases which required emergency LSCS (Failed TOLAC) $13(56.52 \%)$ cases had well developed lower uterine segment with no significant difference between scar 
site and adjacent lower segment.8 (34.78\%)cases had thinning of lower uterine segment. $2(8.69 \%)$ cases had scar dehiscence. There was no case of scar rupture (table 4).

\begin{tabular}{lll}
\multicolumn{3}{l}{ Table 4: Distribution according to intraoperative grading } \\
\hline Intraoperative grade & $\begin{array}{l}\text { Number and \% of } \\
\text { elective LSCS cases }\end{array}$ & $\begin{array}{l}\text { Number and \% of } \\
\text { emergency LSCS cases }\end{array}$ \\
\hline Normal well developed LUS - grade I & $20(24.09 \%)$ & $13(56.52 \%)$ \\
Thinning of LUS - grade II & $39(48.98 \%)$ & $8(34.78 \%)$ \\
Scar dehiscence - grade III & $23(27.71 \%)$ & $2(8.69 \%)$ \\
Scar rupture - grade IV & $1(1.20 \%)$ & 0 \\
Total & 83 & 23 \\
\hline LSCS - Lower segment caesarean section, LUS - Lower uterine segment \\
\hline
\end{tabular}

With the help of Chi-square test for independence the association between scar thickness and scar shape was determined. In our study cases having scar thickness less than $3 \mathrm{~mm}$ ballooning type of scar shape was found in 60 cases and in cases having scar thickness more than $3 \mathrm{~mm}$ triangular shape of scar seen in 102 cases. So there was significant association seen between scar thickness and scar shape. In this study, out of 83 cases having scar thickness less than $3 \mathrm{~mm}$, irregular type of scar border was seen in 67 number of cases and out of 128 cases having scar thickness more than $3 \mathrm{~mm}$, smooth type of scar border was seen 116 cases. The $\mathrm{P}$-value is $\leq 0.0001$ and hence null hypothesis got rejected and so there was significant association seen

\begin{tabular}{lllll}
\multicolumn{4}{l}{ Table 5: Association between scar thickness and scar shape, border, continuity and echogenicity } \\
\hline Parameters & Number of cases & & P value \\
\hline Scar shape & Ballooning & Triangular & Grand total & \\
$\leq 3$ mm scar thickness & 60 & 23 & 83 & p value $<0.0001$ \\
$>3$ mm scar thickness & 26 & 102 & 128 & significant \\
\hline Scar border & Irregular & Smooth & Grand total & p value $<0.0001$ \\
$\leq 3$ mm scar thickness & 67 & 16 & 83 & significant \\
$>3$ mm scar thickness & 28 & 100 & 128 & \\
\hline Scar continuity & Continuous & Discontinuous & Grand total & p value $<0.0001$ \\
$\leq 3$ mm scar thickness & 15 & 68 & 83 & significant \\
$>3$ mm scar thickness & 103 & 25 & 128 & \\
\hline Scar echogenicity & Hyperechoic & Hypoechoic & Isoechoic & p value $<0.0001$ \\
$\leq 3$ mm scar thickness & 13 & 33 & 37 & significant \\
$>3$ mm scar thickness & 76 & 23 & 29 & \\
\hline
\end{tabular}
complication. 3 neonates died on day 5 , two from repeat elective LSCS and 1 from failed TOLAC -emergency LSCS cases. 1 neonate died on day 7 due to sepsis from failed TOLAC -emergency LSCS cases. 20 neonates got admitted in NICU due to various causes not related to scar complications. There was no case of still birth in our study.

\section{Discussion}

TOLAC has been a topic of much debate since past few decades. Ultrasonography can be used to measure the thickness of LUS scar and decide a mode of delivery and outcome of labour. Transabdominal sonography was used in our study to assess the lower uterine segment scar thickness. Rosenberg $^{10}$ et al (1996), Shazia Tazion $^{11}$ et al (2018), Dinesh Kumar $^{12}$ et al (2014), Devindra Kaur $^{13}$ et al (2015) also used trans abdominal sonography in their study to assess the scar thickness. In our study $3 \mathrm{~mm}$ was cut off limit of scar thickness for TOLAC. In Rozenberg $^{10}$ et al (1996) study 3.5 $\mathrm{mm}$ and S. Sen ${ }^{3}$ et al (2004) study 2.5 $\mathrm{mm}$, Devendra Kaur ${ }^{13}$ et al study between scar thickness and scar border. Out of 83 cases having scar thickness less than $3 \mathrm{~mm} 68$ cases had discontinuous scar and out of 128 cases having scar thickness more than $3 \mathrm{~mm} 103$ cases had continuous scar. The P-value is $\leq 0.0001$ and hence, there was significant association seen between scar thickness and scar continuity. In the present study out of 83 cases having scar thickness less than $3 \mathrm{~mm} 33$ cases had hypoechoic scar and out of 128 cases 105(isoechoic + hyperechoic ) cases had good type of scar. There was significant association seen between scar thickness and scar echogenicity (table 5).

Out of 211 cases, 196 cases had good maternal outcome without any complication. 12 cases (6 each of elective LSCS and VBAC) required blood transfusion. 1 case from elective
(2015) $3.5 \mathrm{~mm}$ was the cut off.

Table 6: Comparison of studies according to distribution of cases in terms of mode of delivery

\begin{tabular}{llll}
\hline Name of study & VBAC & $\begin{array}{l}\text { Elective } \\
\text { LSCS }\end{array}$ & $\begin{array}{l}\text { Emergency } \\
\text { LSCS }\end{array}$ \\
\hline S Sen $^{3}$ et al (2004) & $46.48 \%$ & $26.8 \%$ & $26.72 \%$ \\
Vincent YT Cheung et al $^{7}(2005)$ & $31.4 \%$ & $51 \%$ & $17.6 \%$ \\
Caroline A. $^{14}$ et al (2012) & $47 \%$ & $53 \%$ (combined) \\
Dinesh Kumar et al ${ }^{12}(2014)$ & $48.18 \%$ & $9.09 \%$ & $42.72 \%$ \\
Present study & $49.76 \%$ & $39.33 \%$ & $10.9 \%$ \\
\hline
\end{tabular}

The rate of elective LSCS and VBAC in our study was comparable with most of the studies. Emergency LSCS rate of our study was lower than above mentioned studies (table 6). The table 6 also suggests that as scar thickness for TOLAC increases, the success rate of VBAC increases. 
The New Indian Journal of OBGYN. 2021 (January-June);7(2)

Fetal distress and meconium stained liquor were the most common indications for emergency LSCS in studies conducted by Nilanchali Singh $^{6}$ et al (2013) and Ganapathi $\mathrm{T}^{15}$ et al (2018). In our study the commonest indication for emergency repeat LSCS was scar tenderness (30\%), followed by refusal for further trial by the patient in $21 \%$ cases, then non progress of labour in $13 \%$ cases. Fetal distress was indication in $2 \%$, post-datism was in $2 \%$, preeclampsia was in $2 \%$, prolonged PROM responsible for 2 $\%$ emergency LSCS. Number of actual scar given way was in 2 cases $(8.69 \%)$ amongst 23 cases.

Table 7: Comparison of studies according to maternal outcome

\begin{tabular}{lll}
\hline Name of the study & PPH & $\begin{array}{l}\text { Obstetric } \\
\text { Hysterectomy }\end{array}$ \\
\hline Mark B. London $^{16}$ et al 2004 & Not mentioned & $0.26 \%$ \\
Peng Chiong Tan $^{17}$ et al 2007 & $5 \%$ & $0.04 \%$ \\
Dinesh Kumar $^{12}$ et al 2014 & $10 \%$ & $0 \%$ \\
Present Study & $0.47 \%$ & $0 \%$ \\
\hline
\end{tabular}

In a present study percentage of scar dehiscence was $10.9 \%$ in elective repeat LSCS group. There was one case of scar rupture $(0.47 \%)$.We had already separated the cases having scar thickness less than $3 \mathrm{~mm}$ and kept them for elective repeat caesarean section so rate of uterine rupture was less compared to above mentioned studies.

In study by Dinesh Kumar ${ }^{12}$ et al (2014), Atonic PPH occurred in 9 cases with scar thickness between 2-3.5 and in 1 case with scar thickness $>3.5 \mathrm{~mm}$. There was no case of obstetric hysterectomy or maternal mortality in their study. So results of this study in terms of maternal outcome were comparable to our study.

We had kept follow up of neonate of our cases upto 7 days of life .There is no case of IUFD or stillbirth. $96 \%$ of neonate have normal Apgars score at birth, and $11.3 \%$ neonate required NICU admission due to various reasons .Rate of NICU admission was more in repeat LSCS group and reasons for NICU admission was not related to scar thickness. Rate of early neonatal mortality is $\quad 0.4 \%$.

Limitations of study: The measurement of scar thickness is operator dependent and not reproducible. We recommend more studies with more number of cases for further conclusions.

\section{Conclusion}

It was observed that patients with LUS thickness $>3 \mathrm{~mm}$ had high rate of successful TOLAC with favourable fetomaternal outcome. Hence, $3 \mathrm{~mm}$ appears to be a reliable cut off to decide a good healthy scar in predicting uterine dehiscence or rupture in women contemplating vaginal birth after caesarean section. Successful VBAC may be advocated considering clinical factors, counselling and vigilant intrapartum management with scar thickness of $>3 \mathrm{~mm}$, in tertiary care centres.

\section{Conflict of interest: None. Disclaimer: Nil.}

\section{References}

1. Basic E, Basic-Cetkovic V, Kozaric H, Rama A. Ultrasound evaluation of uterine scar after cesarean section. Acta Inform Medica. 2012; 20(3):149-53.

2. Bangal VB, Giri PA, Shinde KK, Gavhane SP. Vaginal birth after cesarean section. N Am J Med Sci. 2013; 5(2):140-4.

3. Sen S, Malik S, Salhan S. Ultrasonographic evaluation of lower uterine segment thickness in patients of previous cesarean section. Int J Gynecol Obstet. 2004; 87(3): 215-9.

4. Naji O, Daemen A, Smith A, Abdallah Y, Saso S, Stalder C, et al. Changes in Cesarean section scar dimensions during pregnancy: A prospective longitudinal study. Ultrasound Obstet Gynecol. 2013;41(5):556-62.

5. Mohammed ABF, Al-Moghazi DA, Hamdy MT, Mohammed EM. Ultrasonographic evaluation of lower uterine segment thickness in pregnant women with previous cesarean section. Middle East Fertil Soc J. 2010;15(3):188-93.

6. Singh N, Tripathi R, Mala YM, Dixit R. Scar thickness measurement by transvaginal sonography in late second trimester and third trimester in pregnant patients with previous cesarean section: does sequential change in scar thickness with gestational age correlate with mode of delivery? J Ultrasound. 2015;18(2):173-8.

7. Cheung VYT. Sonographic Measurement of the Lower Uterine Segment Thickness: Is it Truly Predictive of Uterine Rupture? J Obstet Gynaecol Canada. 2008;30(2):148-51.

8. Ash A, Smith A, Maxwell D. Caesarean scar pregnancy. BJOG An Int J Obstet Gynaecol. 2007;114(3):253-63.

9. Qureshi B, Inafuku K, Oshima K, Masamoto H, Kanazawa K. Ultrasonographic Evaluation of Lower Uterine Segment to Predict the Integrity and Quality of Cesarean Scar during Pregnancy: A Prospective Study. Tohoku J Exp Med. 1997; 183(1):55-65.

10. Rozenberg P, Goffinet F, Philippe HJ, Nisand I. Ultrasonographic measurement of lower uterine segment to assess risk of defects of scarred uterus. Lancet. 1996; 347(8997): 281- 4. 
The New Indian Journal of OBGYN. 2021 (January-June);7(2)

11. Tazion S, Hafeez M, Manzoor R, Rana T. Ultrasound predictability of lower uterine segment cesarean section scar thickness. J Coll Physicians Surg Pakistan. 2018; 28(5): 361-4.

12. Kumar D, Mohan N, Sharma N. Evaluation of lower uterine segment in women with previous cesarean section by transabdominal ultrasonography \& its relation to feto-maternal outcome. JK Sci. 2014;16(2): 71-5.

13. Kaur D, Singh H. Study of obstetric and perinatal outcome in previous cesarean by sonographic evaluation of scar thickness of lower uterine segment at term. International Journal of Scientific Reports. 2015;1(3):159-62.

14. Crowther CA, Dodd JM, Hiller JE, Haslam RR, Robinson JS. Planned vaginal birth or elective repeat caesarean: Patient preference restricted cohort with nested randomised trial. PLoS Med. 2012; 9(3).

15. Ganapathi T, Chaudhari HK. Ultrasonographic measurement of uterine lower segment scar thickness in cases of previous one caesarean section and obstetric outcome. Int J Reprod Contraception, Obstet Gynecol. 2018;7(11): 4454.

16. Landon MB, Hauth JC, Leveno KJ, Spong CY, Leindecker S, Varner MW, et al. Maternal and perinatal outcomes associated with a trial of labor after prior cesarean delivery. N Engl J Med. 2004; 351(25): 2581-9.

17. Tan PC, Subramaniam RN, Omar SZ. Labour and perinatal outcome in women at term with one previous lower-segment Caesarean: A review of 1000 consecutive cases. Aust New Zeal J Obstet Gynaecol. 2007;47(1):31-6.

\section{Bhakti Kalyankar ${ }^{1}$, Vijay Kalyankar ${ }^{2}$, Shrinivas Gadappa $^{3}$, Kokila Ashok Gaikwad ${ }^{4}$}

${ }^{1}$ Professor, Department of Obstetrics \& Gynaecology, Government Medical College \& Hospital, Aurangabad, Maharashtra, India; ${ }^{2}$ Associate Professor, Department of Obstetrics \& Gynaecology, Government Medical College \& Hospital, Aurangabad, Maharashtra, India;

${ }^{3}$ Professor and HOD, Department of Obstetrics \& Gynaecology, Government Medical College \& Hospital, Aurangabad, Maharashtra, India; ${ }^{4}$ Resident, Department of Obstetrics \& Gynaecology, Government Medical College \& Hospital, Aurangabad, Maharashtra, India. 